\title{
Leadership Efficacy and Women Leaders' Responses to Stereotype Activation
}

\author{
Crystal L. Hoyt \\ University of Richmond \\ Jim Blascovich \\ University of California, Santa Barbara
}

\begin{abstract}
The role of leadership efficacy in women's reactance responses to stereotype-based leadership role expectations was examined in two laboratory studies. Participants, selected on the basis of leadership efficacy scores, served as leaders of ostensible three-person groups. Half were primed with the gender leadership stereotype. An immersive virtual environment designed for this research served as the leadership setting. Results indicated that the effects of stereotype activation on women leaders were moderated by leadership efficacy such that high efficacy leaders exhibited more positive, reactance responses (increased perceived performance, increased rated performance, greater domain identification, and higher well-being) than low efficacy leaders. Additionally, perceived performance mediated the domain identification and well-being effects of stereotype activation on high and low efficacy leaders.
\end{abstract}

KEYWORDS gender, leadership, reactance, self-efficacy, small groups, stereotypes

Organizational leaders make important and far-reaching decisions that impact many aspects of society. In the US relatively few of these powerful positions are held by women who, despite increased representation in organizations, remain underrepresented in the upper echelons of American business and government. For example, women represent only $23.8 \%$ of Chief Executive Officers of all organizations in the United States (Bureau of Labor Statistics, 2006), and the numbers are even more bleak when we look to Fortune 500 companies where women hold a mere $7.9 \%$ of the highest titles and there are only 11 women CEOs (2.2\%; Catalyst, 2002; Joyce, 2006). Eagly and
Karau (2002) recently proposed an explanation for the dearth of women in top leadership roles. According to their role congruity theory, the descriptive and prescriptive aspects of the female gender stereotype are incongruent with the leadership role, and that incongruity leads to prejudice against women leaders. In addition to leading to prejudice against women leaders, the

\footnotetext{
$\overline{\text { Author's note }}$

Address correspondence to Crystal L. Hoyt, Jepson School of Leadership Studies, University of Richmond, Richmond, VA, 23173, USA [email: choyt@richmond.edu]
} 
gender leader stereotype may also directly affect women in leadership positions. The goal of this research is to understand how this stereotype influences women in the leadership role.

\section{Gender stereotypes and the leadership role}

Stereotypic beliefs about gender differences are pervasive, well documented, and highly resistant to change (Dodge, Gilroy, \& Fenzel, 1995; Heilman, 2001). Gender stereotypes encompass stereotypic beliefs about the attributes of women and men that prescribe how men and women should, or ought to, be ${ }^{1}$ (Burgess \& Borgida, 1999; Glick \& Fiske, 1999). Descriptive stereotypical attributes of men include 'agentic' characteristics emphasizing confidence, control, and assertiveness whereas stereotypical attributes of women include 'communal' characteristics highlighting a concern for others (Broverman, Vogel, Broverman, Clarkson, \& Rosenkrantz, 1972; Eagly, 1987; Eagly, Wood, \& Diekman, 2000; Heilman, 2001). Although women and men are viewed as differing on other traits (Deaux \& Lewis, 1983, 1984; Eckes, 1994), the agentic and communal stereotypical attributes directly relate to the leadership domain. Substantial empirical research supports the prescriptive nature of gender stereotypes (Glick \& Fiske, 1996; Williams \& Best, 1990; Wood, Christensen, Hebl, \& Rothgerber, 1997). Accordingly, not only should individuals conform to their stereotypic description, but they should also avoid behaviors that are incompatible with the stereotype (Heilman, 2001).

Role congruity theory maintains that the agentic qualities deemed necessary in the leadership role are incompatible with the predominantly communal qualities associated with women (Eagly \& Karau, 2002). This gender leader stereotype (aka think-manager-think-male stereotype) is well validated (Sczesny, 2003). Top management positions and executive level jobs are almost always thought to require an achievement-oriented aggressiveness and an emotional toughness that is antithetical to the female gender stereotype. Substantial empirical evidence indicates that stereotypically male qualities are thought necessary for successful leaders, and good leaders are described predominantly by masculine attributes (Arkkelin \& Simmons, 1985; Martell, Parker, Emrich, \& Crawford, 1998; Powell \& Butterfield, 1979, 1984, 1989; Rosenwasser \& Dean, 1989; Schein, 1973, 2001).

\section{Biases in the perception and evaluation of female leaders}

Individuals have incongruent expectations for female leaders: those based on gender stereotypes and those based on leadership roles. The perceived incongruity between the female gender role and the leadership role leads to prejudice that can account for the numerous findings that indicate less favorable attitudes toward female than male leaders, greater difficulty for women to attain top leadership roles, and greater difficulty for these women to be viewed as effective in these roles (Eagly \& Karau, 2002). For example, Heilman and colleagues have shown that while women managers are seen as more similar to successful managers than women in general, they are rated as more different from successful managers than are male managers (Heilman, Block, \& Martell, 1995; Heilman, Block, Martell, \& Simon, 1989). Researchers have also demonstrated that women are presumed to be less competent leaders than men and less worthy of the leadership position across a variety of contexts (Boldry, Wood, \& Kashy, 2001; Carli \& Eagly, 2001; Heilman, 2001; Ridgeway, 2001; Schein, 2001). Additionally, research has revealed that in order to be influential leaders, women need to combine communal qualities (e.g. warmth and friendliness) with agentic qualities (e.g. competence and directiveness; Carli, 2001; Eagly, Makhijani, \& Klonsky, 1992; Rudman \& Glick, 2001). While empirical research clearly establishes the impact of stereotypes on the perception and evaluation of women leaders, the literature is less clear on the impact of these stereotypes on women leaders themselves; the goal of the current research is to examine this impact. 


\section{The impact of stereotype activation on the target}

Responses to stereotypes vary from deleterious threat responses to more benign reactance responses. Initial research into the impact of stereotypes on targets generally demonstrated the pernicious effects of stereotype threat, defined as the apprehension that individuals feel when they are at risk of confirming a negative stereotype about their group (Aronson, Quinn, $\&$ Spencer, 1998). Stereotype threat undermines individuals' assessments of their abilities and results in decreased performance; it has been shown to play an important role in the underperformance of minorities (Aronson et al., 1998; Steele \& Aronson, 1995). Stereotype vulnerability effects have been demonstrated in the leadership domain. Davies, Spencer, and Steele (2005) found that exposure to stereotypic commercials undermines women's leadership aspirations; however, presenting women with an identity safe environment eliminates this vulnerability. Additionally, Bergeron, Block, \& Echtenkamp (2006) found that men outperformed women on a managerial task but only when it was a masculine sex role-typed task; this effect disappeared on a feminine sex roletyped task.

As is clear from the responses of women in identity safe environments (Davies et al., 2005) and feminine sex-typed tasks (Bergeron et al., 2006), stereotypes are not always met with vulnerability responses. Indeed, research has shown that when gender stereotypes are primed explicitly women sometimes respond by engaging in stereotype countering behaviors; that is, they demonstrate stereotype reactance (Kray, Thompson, \& Galinsky, 2001). Brehm's (1966) psychological reactance theory contends that people respond to perceived threats to their freedom (such as stereotyped expectations of inferiority) by attempting to reassert their freedom (engaging in counterstereotypical behavior). For example, Kray and colleagues (2001) showed that women blatantly presented with the gender and bargaining stereotype outperform men at the bargaining table. Additionally, Kray and colleagues found that participants need to possess sufficient power in order to react against the stereotype (Kray, Reb, Galinsky, \& Thompson, 2004).

This distinction between stereotype vulnerability and stereotype reactance is similar to the distinction between stereotype assimilation and contrast (Stoddard, Kliengklom, \& Ben-Zeev, 2003). Assimilation effects refer to performance deficits resulting from stereotype threat. Contrast effects refer to increases in performance by individuals primed with negative stereotypes regarding their group. Stoddard and colleagues examined the moderating role of the subtlety of the stereotype prime on women's desire to take on a leadership role. Specifically, they found that subtle stereotype activation evoked assimilation such that women were less likely to desire a leadership position, whereas blatant stereotype activation resulted in a heightened desire to assume a leadership position.

\section{The role of efficacy in the impact of stereotype activation}

Self-efficacy, a key construct derived from Bandura's social-cognitive theory (1986), is defined as 'belief in one's capabilities to organize and execute the courses of action required to produce given attainments' (Bandura, 1997, p. 3). Empirical studies yield consistent findings revealing that self-efficacy influences thought patterns, stress reactions, and coping; what people choose to do; their persistence in the face of difficulty; how much effort they put forth; and performance (Bandura, 1982, 1986; Bandura \& Cervone, 1983; Bandura \& Wood, 1989; Barling \& Beattie, 1983; Campbell \& Hackett, 1986; Hill, Smith, \& Mann, 1987; Lent, Brown, \& Larkin, 1987; Taylor, Locke, Lee, \& Gist, 1984).

\section{Self-efficacy as a moderator of stereotype activation effects}

Self-efficacy has been shown to moderate responses to work-related stressors and is associated with the ways in which individuals cope with stressors (Jex \& Bliese, 1999; Stumpf, Brief, \& Hartman, 1987). Individuals high in self-efficacy adopt a more problem-focused coping strategy; those lower in self-efficacy 
assume a more emotion-focused approach. These approaches are not equally efficient; problem-focused coping is associated with more adaptive responses than emotion-focused coping (Lazarus \& Folkman, 1984). Construing stereotype activation as a potential stressor, reactions to stereotype activation seem likely to be moderated by levels of self-efficacy.

Recent research supports the prediction that self-efficacy moderates responses to stereotype activation. Solo status, or being the lone woman in a group of men, is a sufficient situational cue to induce stereotype activation for women (Inzlicht \& Ben-Zeev, 2000; Sekaquaptewa \& Thompson, 2003). White and Gardner (2003) examined the impact of task-specific efficacy on the effect of solo status on math performance. They found that women's efficacy moderated their performance on a math test when they were the solo female group member. Specifically, highly confident women performed better in the stereotype activating solo condition than less confident women. In the current research, selfefficacy for leadership is predicted to moderate women's responses to stereotype activation in the leadership domain such that those with high levels of efficacy will demonstrate reactance responses.

\section{Hypotheses}

In the current research, stereotypes were primed in a blatant manner, and self-efficacy was examined as a potential moderator of stereotype reactance effects. ${ }^{2}$ We hypothesized that leadership efficacy would interact with stereotype activation on the following responses: perceived and rated performance, domain identification, and psychological well-being.

\section{Perceived and rated performance}

In situations, such as leadership situations, that often lack clear and instantaneous measures of effectiveness, individuals' perceptions of how well they performed become a very important source of immediate feedback to the self. Perceptions of successful performance can convince people that they have what it takes to succeed in a domain which can in turn result in perseverance, resilience in the face of adversity, higher accomplishments, and success at new activities (Bandura, 1997). Consequently, we hypothesized that leadership efficacy would interact with stereotype activation such that high efficacy leaders would report higher levels of perceived performance when the stereotype was primed than when neutral material was primed. Additionally, based on the stereotype reactance literature we predicted that ratings of performance would show that stereotype activation increases the performance of high efficacy leaders compared to the control condition.

\section{Domain identification}

Stereotype threat theory proposes that one way individuals may cope with the threat is by disidentifying with the stereotype-relevant domain. That is, individuals' self-perceptions and self-concept become independent of performance in that domain. Such disidentification can diminish achievement in the domain (Steele \& Aronson, 1995). For example, stigmatized individuals (e.g. African-Americans) are more prone than their non-stigmatized counterparts to disidentify with academics, academic performance situations being a domain in which stereotype threat often occurs (Major, Spencer, Schmader, Wolfe, \& Crocker, 1998). Consequently, we hypothesized that leadership efficacy would interact with stereotype activation such that high efficacy leaders would show reactance by reporting more identification with leadership in the stereotype activation compared to the control condition.

\section{Psychological well-being}

Previous research has shown that negative stereotypes can adversely affect the psychological well-being of the targets (Swim, Hyers, Cohen, \& Ferguson, 2001). Psychological well-being includes, but is not limited to, reported levels of self-esteem and depressed affect. Consequently, we hypothesized that leadership efficacy would interact with stereotype activation such that high efficacy leaders would report greater levels of well-being in the stereotype activation compared to the control condition. 


\section{Mediational hypotheses}

Based on self-perception theory and self-esteem theory, self-perception was hypothesized to mediate the proposed interaction effects on domain identification and psychological well-being. First, according to Bem's self-perception theory (1967), individuals infer their own traits and attitudes by observing their own behavior. Thus, we hypothesized that individuals' perceptions of their leadership performance would influence their inference about how strongly they view themselves as leadership-oriented persons; that is, how much they identify with the domain of leadership. Second, we hypothesized perceptions of performance on the stereotype domain relevant task would directly influence individuals' well-being. That is, perceiving that one performed well on the leadership task and thus disconfirmed the negative stereotype would lead to increased psychological well-being (see Figure 1 for hypothesized mediational relationships.)

\section{Overview of present research}

\section{Procedural overview}

These hypotheses were addressed in two experimental studies. Each of these studies employed a paradigm designed to test the hypotheses in a controlled, small group, leadership situation. Given that the primary goal of these studies was to demonstrate the differential effects of stereotype activation on high and low efficacy leaders, participant selection was based on leadership efficacy. Participants took part in a group task as the 'randomly assigned' leader of a three-person group. Half of the participants were primed with the gender leader stereotype before taking the leadership role in an employee hiring decision task.

\section{Immersive virtual environment technology}

Historically, experimental investigations into leadership and other facets of group life have employed impactful manipulations to induce participants to experience certain affects, cognitions, and/or motivations. Common simulation techniques include the use of vignettes, role-playing, confederates, and verbal instructions. Recent technological advances have provided researchers with a tool to facilitate compelling manipulations: immersive virtual environment technology (IVET). We define a virtual environment as one providing synthetic sensory information that leads to perceptions of

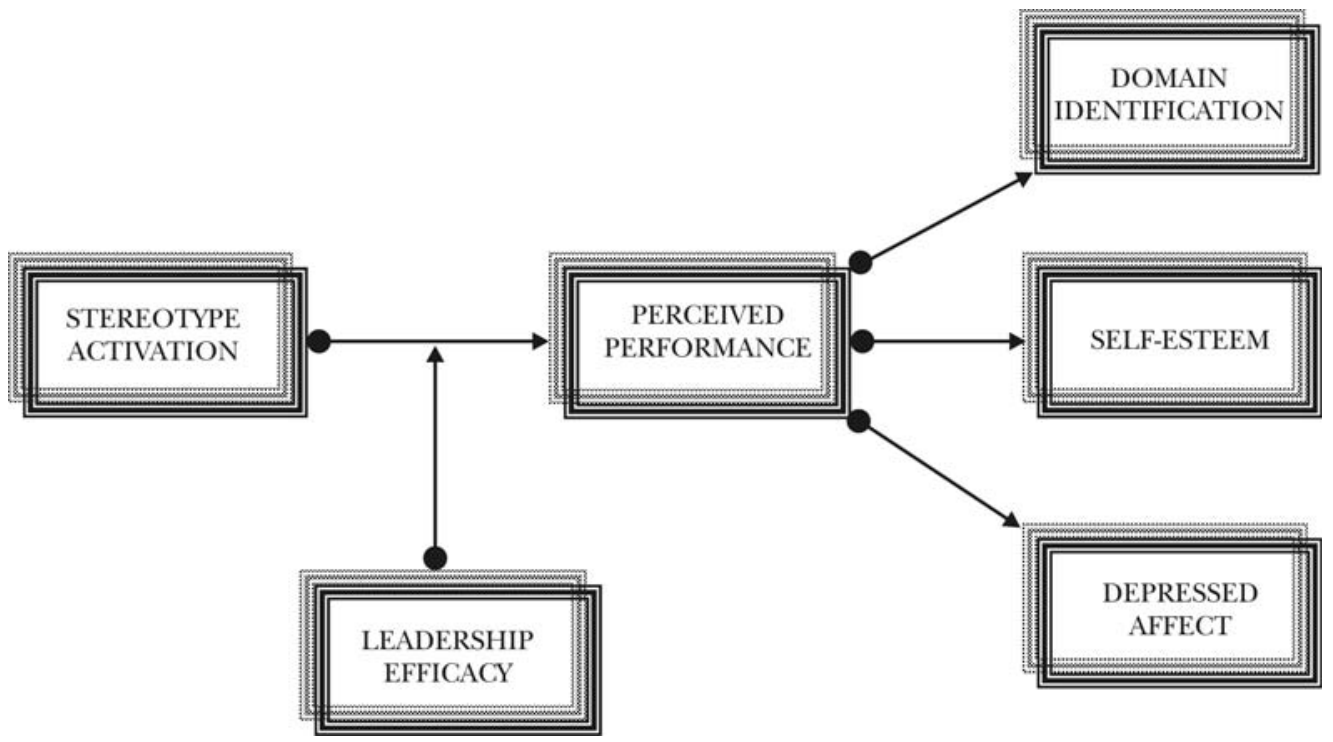

Figure 1. Perceived performance as a hypothesized mediator of the interactive effects of stereotype activation and leadership efficacy on domain identification, self-esteem, and depressed affect. 
environments and their contents as if they are not synthetic (Blascovich et al., 2002).

Although relatively new, IVET technology has been noted for many of the methodological advantages it provides (see Blascovich et al., 2002 for a detailed description). First, it provides superb control over the confederates' (followers') demographic characteristics, such as sex and ethnicity, and behaviors, assuring exact replications of confederates' behaviors across participants. Additionally, IVET diminishes the need for live research confederates, thus increasing efficiency in conducting experiments. In terms of operation, our IVET system consisted of three subsystems: a) a body location and head tracker, b) a graphics rendering computer, and c) an audiovisual head-mounted display (HMD). Translation and orientation information regarding the user's body and head is sensed and recorded by the trackers, which in turn inform the rendering computer, which then generates and projects visual and auditory stimuli to the user's $\mathrm{HMD}^{3}$ (see Figure 2).

These experiments were conducted in a laboratory that contained three rooms in which three people, each located in a separate room, can interact together within a virtual conference room consisting of three people sitting around a table. The leadership task took place within this immersive virtual conference room with, what the leaders were led to believe were, two other research participants, Chris (male) and Michelle (female). Participants were led to believe that the two other participants would don their HMDs in the two other laboratory rooms and that they would all be networked together into one virtual conference. In the virtual room the participant/leader sat across the conference table from the two ostensible group members who were programmed to generate random nonverbal body movements, including eye blinks, head movements, and small facial expressions (see Figure 2).

\section{Study 1}

This study tested the hypotheses that leadership efficacy would interact with stereotype activation on perceived leadership performance, rated
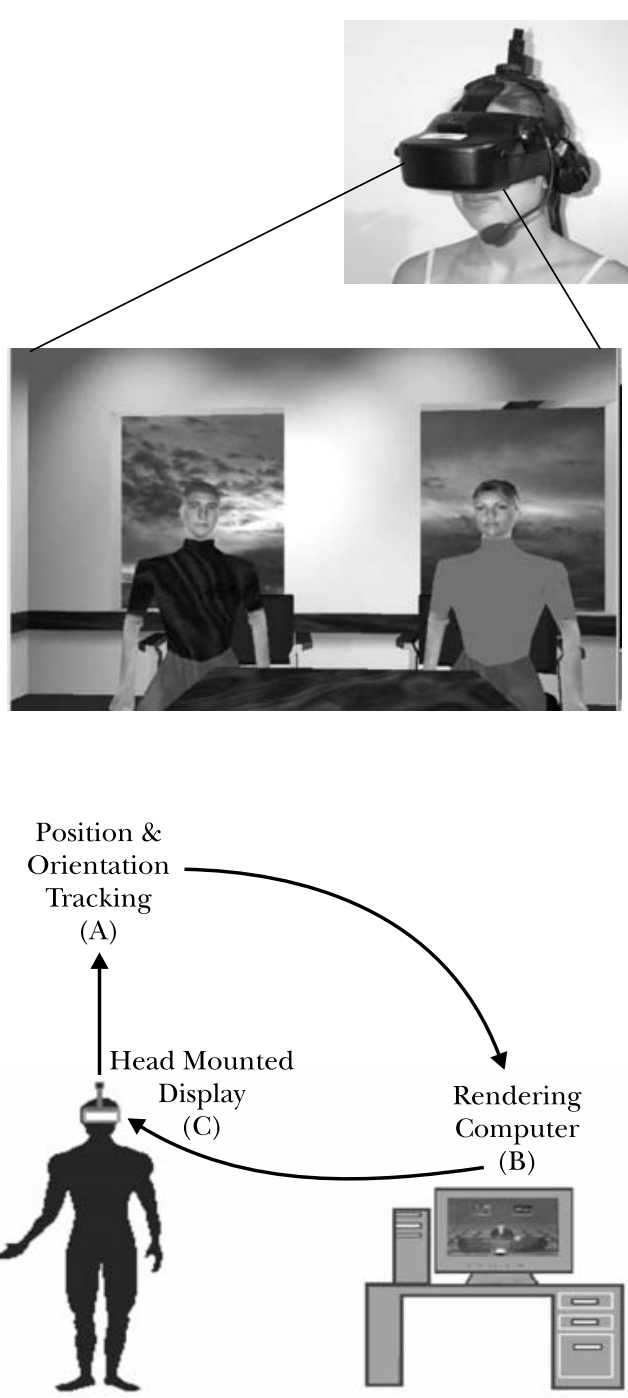

Figure 2. The leader's view of the two followers during the meeting in the immersive virtual environment and the immersive virtual display system.

leadership performance, and leadership domain identification and that the latter moderation effect would be mediated by perceived performance.

\section{Method}

Participants and design Fifty-four female undergraduate students enrolled in Introductory 
Psychology at a major research university served as participants and were given either credit toward the Introductory Psychology course research participation requirement or US $\$ 10$ for their participation. Of the 54, one refused to perform the leadership task, leaving 53 participants in the final sample. The experiment employed a 2 (Leadership Efficacy: High or Low) $\times 2$ (Stereotype Activation: Primed or Not) between-subjects quasi-experimental design.

Participant selection: Self-efficacy for leadership (SEL) Participants were selected on the basis of SEL scores obtained during a prescreening session at the beginning of the term. Murphy (1992) developed the SEL to measure individuals' self-efficacy regarding their general leadership abilities. The SEL has been well-validated in predicting leadership, group, and organizational outcomes (Chemers, Watson, \& May, 2000; Murphy, 2002; Murphy, Chemers, Kohles, \& Macaulay, 2004; Watson, Chemers, \& Preiser, 1996). Participants rated their leadership abilities on eight 5-point Likert-type scales from 1 (strongly disagree) to 5 (strongly agree). Example statements include 'I am confident of my ability to influence a work group that I lead,' and 'I know what it takes to keep a work group running smoothly' $(\alpha=.93)$. Those scoring in the upper and lower quartiles of the distribution of prescreening scores were eligible for participation in this study.

Experimental overview Participants were randomly assigned to receive the stereotype or the neutral prime. All participants ostensibly participated in a group task as the randomly assigned leader of the three-person group. Participants were run individually. Upon arrival, participants were greeted by one of two male experimenters. They were told that they were randomly selected to be the group leader and were asked to arrive earlier than the other two group members. After this general introduction to the experiment, the stereotype activation manipulation (see below) was introduced. The participants (i.e. leaders) then received instructions regarding the group task and were given seven minutes to prepare for an audio-recorded three-minute meeting with the other two "participants'. The participants were then immersed in a virtual world for a three-minute meeting, supposedly with the other participants. ${ }^{4}$ Following this, the participants completed the perceived performance and domain identification questionnaires, while the other group members were ostensibly completing the task. Participants were then thoroughly debriefed, thanked, and given course credit or payment.

Stereotype activation manipulation To prime the gender leader stereotype, participants were given a folder to peruse while waiting for the experimenter to return. For the stereotype activation condition, the folder contained media images of male leaders and information regarding the gender gap in top leadership roles; for example, participants were told that 'in nearly all major corporations, the military and political offices, men outnumber women in top leadership roles, and there seems to be a steady gap in men and women in top leadership roles. Though women represent $46 \%$ of the U.S. workforce, they hold only about $6 \%$ of executive titles like CEO, chairwoman, and executive vice president. And only four women hold CEO positions at Fortune 500 companies' ${ }^{5}$ In the control condition, the folder contained images of and information regarding the virtual reality lab. To augment the stereotype activation manipulation, participants in the experimental condition were also told by the experimenter that the research was aimed at better understanding gender differences in leadership abilities; those in the control condition were simply told that the research was designed to better understand leadership abilities.

Leadership task scenario Participants occupied the role of President of the Human Resources division of James Frick Inc., whose charge was to lead (i.e. chair) a selection committee hiring a new junior associate. Specifically, they were assisted by two Vice-Chairs; that is, the other two 'participants'. Leaders were given a memo from the CEO of James Frick Inc. explaining the need for the new associate in detail and were given two applicant information packets. They were informed that the two Vice-Chairs 
would be given the same memo and packets of applicant information after the meeting. The participants' responsibility was to examine the materials and prepare for a three-minute meeting with the Vice-Chairs. Their job was to explain the task to the followers and advise them on how they thought the followers should go about accomplishing the task. More generally, they were asked to influence and motivate them to make the best hiring decision possible. Within an immersive virtual conference room, the leaders held a three-minute meeting with the two Vice-Chairs; this meeting allowed for only one-way communication from the leader to the followers. This task was fashioned after the increasingly common virtual workplace.

Measures Participants responded to all measures on a 7-point Likert-type scale ranging from -3 (strongly disagree) to 3 (strongly agree).

Perceived performance Leaders were asked to rate their own performance on two items. The following items were created to assess the participants' perceived performance: 'I performed well on the leadership task I just completed', and 'I am confident that I performed well' $(\alpha=.87)$.

Rated performance All audiotapes were independently coded by two trained raters blind to leadership efficacy and stereotype activation condition. The rated performance scale consisted of five items: vigor (how energetic, active, and lively they were), anxiety (nervousness; reverse coded), task explanation (how well they explained the problem), vision (how well they articulated a clear vision for the company), and authority (how knowledgeable, direct, and down to business they were). Performance assessments were made on a 9-point scale. Interrater reliability was computed using a Pearson's $r(r=.89$, $p<.001)$.

Domain identification Domain identification was operationalized as the extent to which the participants identified with being, and saw themselves as, a leader. Fashioned after Steele and Aronson's (1995) academic identification measures, the following items were created to assess leadership identification: 'Leadership is important to me', 'I am a leadership-oriented person', 'It is important for me to be selected group leader', 'I am a good leader', and 'Leadership skills will be important to my career' $(\alpha=.88)$.

Manipulation check To assess the efficacy of the stereotype activation manipulation, participants were asked to rate the following statement: 'In leadership roles, people $f$ my gender often face biased evaluations'.

\section{Study 2}

Due, in part, to the small sample size for Study 1 $(n=53)$, we conducted Study 2 as a replication as well as an extension of Study 1 . The methods for both studies are presented and, for simplification, the data from both studies are analyzed together. Study 2 was extended to test well-being responses. Thus, efficacy was expected to interact with stereotype activation on perceptions and ratings of leadership performance, identification with the domain of leadership, and wellbeing responses. Additionally, this study tested the prediction that the interaction between leadership efficacy and stereotype activation on domain identification and well-being would be mediated by perceived performance.

\section{Method}

Participants and design Seventy-five female undergraduate students attending a major research university participated in this study. Participants were given either credit toward the Introductory Psychology course research participation requirement or US $\$ 10$ for their participation. Of the original 75 participants, 3 were dropped from analyses for either not understanding the experimental instructions or not fluently speaking English. Thus, there were 72 participants in the final sample. The design of Study 2 was identical to that of Study 1 and participants were selected in the same manner.

Procedures The procedures for Study 2 were basically the same as in Study 1 with two minor 
changes. First, both experimenters in Study 1 were male; four female and one male experimenter were employed in the current study. Additionally, the experimental instruction set was standardized such that most instructions were given to the participants via an audio-recording rather than via the experimenter. The remainder of the methodology remained identical to Study 1; the stereotype activation manipulation, the immersive virtual environment, and the task were the same across studies.

Measures Again, participants responded to all measures on a 7-point Likert-type scale ranging from -3 (strongly disagree) to 3 (strongly agree).

Perceived performance, rated performance, domain identification, and manipulation check The perceived performance and domain identification measures remained identical to those in Study 1 ( $\alpha=.93$ and $\alpha=.90$, respectively). Also, the performance rating procedures were identical $(\mathrm{r}=.80, p<.001)$ and the same manipulation check item was used.

Self-esteem Self-esteem was assessed with a 6-item measure adapted from Heatherton and Polivy's (1991) state self-esteem measure $(\alpha=.85)$. Three items assessed performance self-esteem: 'I feel frustrated or rattled by my performance', 'I feel that I am having trouble understanding things', and 'I feel like I am not doing well'. The remaining three items assessed social self-esteem: 'I feel displeased with myself', 'I am worried about looking foolish', and 'I feel concerned about the impression I am making'. Both performance and social self-esteem resulted in similar outcomes, so, for simplicity, we have combined the measures into a general self-esteem measure.

Depressed affect The depressed affect scale consisted of six items adapted from the Multiple Affect Adjective Check List (MAACL) (Lubin, Zuckerman, \& Woodward, 1985). Participants indicated their agreement to the following items: 'I feel discouraged', 'I feel distressed', 'I feel pessimistic about the future', 'I feel sad', 'I feel mortified', and 'I feel hopeless' $(\alpha=.85)$.

\section{Results}

The manipulation check and the first set of moderation hypotheses were tested with the data from both studies. To test the hypotheses dependent variables were analyzed with a series of 2 (Leadership Efficacy) $\times 2$ (Stereotype Activation) $\times 2$ (Study) between-subjects analyses of variance. Study was included as a factor in the analyses to ensure equivalence in the data from the two studies.

Manipulation check As expected, participants in both studies who received the stereotype activation manipulation were more likely to report that people of their gender face biased evaluations $(M=1.26, S D=1.20)$ than those who did not receive the stereotype manipulation $(M=0.57 ; S D=1.58)(F(1,117)=8.04, p<.01$, $\left.\eta^{2}=.06\right)$. The factor of study did not have a main effect nor did it interact with condition or leadership efficacy on the manipulation check. There was no main effect for leadership efficacy $(p>.35)$ and there was no interaction between leadership efficacy and stereotype activation $(p>.45)$.

\section{Moderation hypotheses: Perceived performance, rated performance, and domain identification}

Perceived performance The Cronbach's alpha of the perceived performance scale for the combined data was .91. These analyses revealed that the factor of study did not have a main effect nor did it interact with the two independent variables on perceived performance. Additionally, there was no main effect for stereotype activation on perceived performance $(p>.60)$. There was a main effect of efficacy such that high efficacy women perceived they performed better $(M=0.78, S D=1.42)$ than low efficacy women $(M=-.64, S D=1.41)(F(1,117)=28.52$, $\left.p<.001, \eta^{2}=.20\right)$. Additionally, there was a significant interaction $(F(1,117)=9.08, p<.01$, $\eta^{2}=.07$; see Figure 3) such that high efficacy women primed with the stereotype reported 
higher levels of perceived performance ( $M=1.17$, $S E=0.25)$ compared to those primed with the neutral material $(M=0.29, S E=0.27)$ (simple $\left.F(1,117)=5.74, p<.05, \eta^{2}=.05\right)$. Additionally, low efficacy women primed with the stereotype reported marginally lower levels of perceived performance $(M=-0.94, S E=0.24)$ than those primed with the neutral material $(M=$ $-0.30, S E=0.25$; simple $F(1,117)=3.42, p<.07$, $\left.\eta^{2}=.03\right)$.
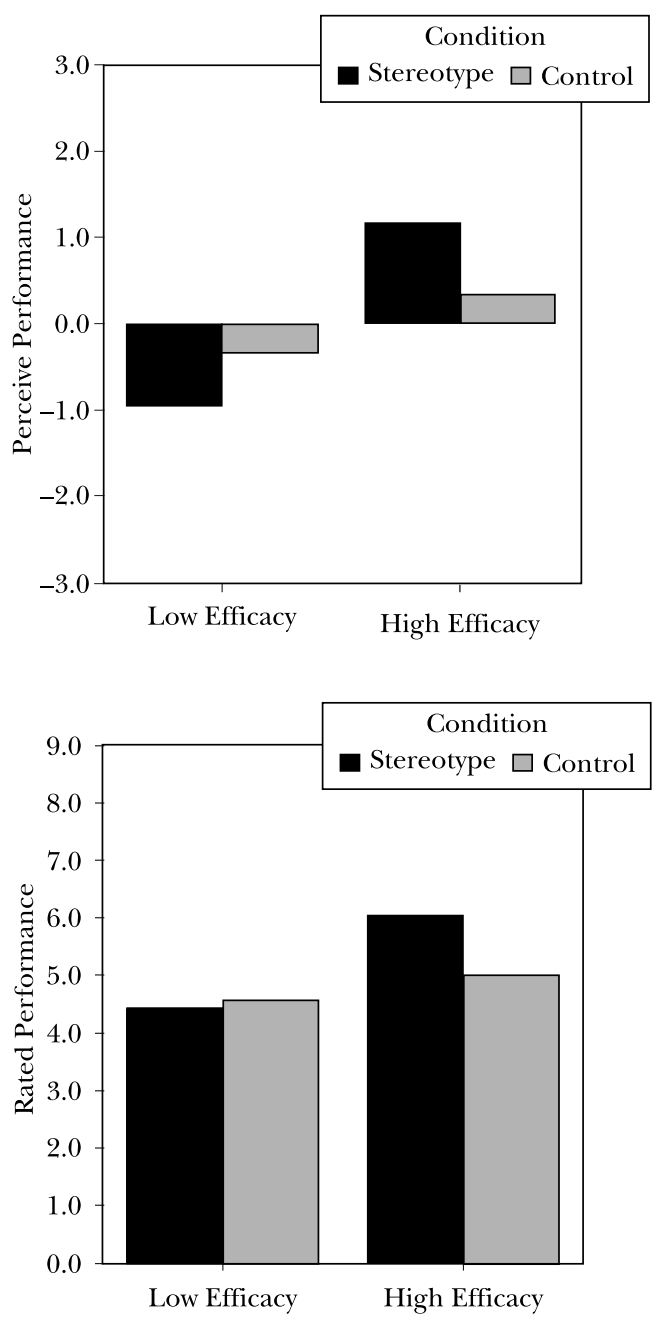

Figure 3 Continued

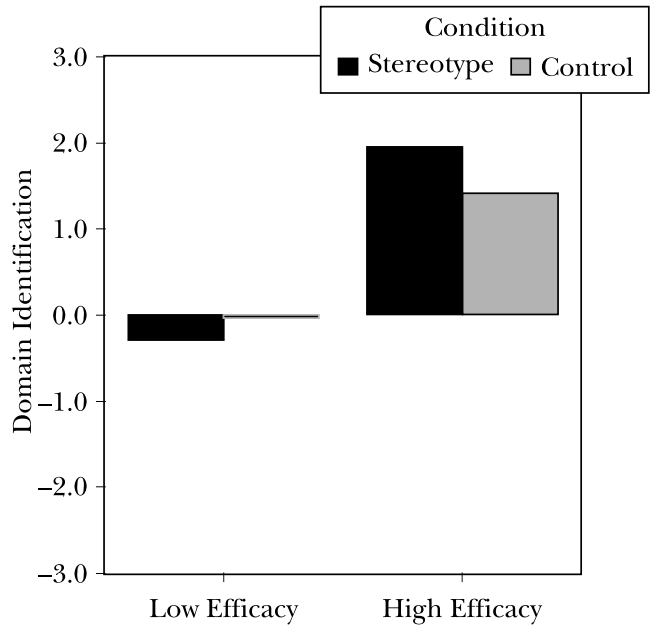

Figure 3. The impact of leadership efficacy and stereotype activation on perceived leadership performance, rated leadership performance, and domain identification.

Rated performance Unfortunately, a few of the tapes were inaudible, leaving 109 data points for these analyses. Interrater reliability for the combined data was $\mathrm{r}=.83, p<.001$. The factor of study did not have a main effect nor did it interact with the two independent variables on rated performance. Additionally, there was no main effect for stereotype activation on rated performance $(p>.15)$. There was a main effect of efficacy such that high efficacy women were rated as performing better $(M=5.51, S D=1.63)$ than low efficacy women $(M=4.48, S D=1.85)$ $\left(F(1,101)=9.68, p<.05, \eta^{2}=.09\right)$. Additionally, there was a marginally significant interaction $\left(F(1,101)=2.90, p=.09, \eta^{2}=.03\right.$; see Figure 3$)$ such that high efficacy women primed with the stereotype had higher levels of rated performance $(M=6.05, S E=0.35)$ compared to those primed with the neutral material $(M=5.02, S E=0.35)$ $\left(\right.$ simple $\left.F(1,101)=4.28, p<.05, \eta^{2}=.04\right)$.

Domain identification The Cronbach's alpha of the domain identification scale for the combined data was .89. The study factor did not have a main effect on domain identification, but it did interact with efficacy on domain identification $(F(1,117)=7.94, p<.01)$. The interaction was such that high efficacy leaders had higher domain 
identification in Study 2 than Study 1, and low efficacy leaders had lower identification in Study 2 than Study 1; in other words, the main effect of efficacy on domain identification was stronger in Study 2. The main effect of stereotype activation on domain identification was not significant $(p>.50)$. There was a significant main effect of efficacy $\left(F(1,117)=105.32, p<.001, \eta^{2}=.47\right)$, with high efficacy women identifying more with the domain of leadership $(M=1.72, S D=0.88)$ than low efficacy women $(M=-.15, S D=1.07)$. Also, there was a significant interaction between leadership efficacy and stereotype activation on domain identification $(F(1,117)=5.91, p<.05$, $\eta^{2}=.05$ ) (see Figure 3); high efficacy women primed with the stereotype reported higher levels of domain identification $(M=1.93, S E=0.17)$ than those primed with the neutral material $(M=1.41, S E=0.18$; simple $F(1,117)=4.28$, $\left.p<.05, \eta^{2}=.04\right)$. Low efficacy leaders primed with the stereotype reported similar levels of domain identification $(M=-.27, S E=0.16)$ to those in the control condition $(M=0.05$, $S E=0.17)($ simple $F(1,117)=1.82, p=.18)$.

Moderation hypotheses: Self-esteem and depressed affect Data to test these hypotheses were only collected in Study 2. To test the hypotheses we analyzed the dependent variables with a series of 2 (Leadership Efficacy) $\times 2$ (Stereotype Activation) between-subjects analyses of variance.

Self-esteem The main effect of stereotype activation on self-esteem was not significant $(p>.15)$. There was a significant main effect of efficacy $\left(F(1,67)=16.12, p<.001, \eta^{2}=.19\right)$, with high efficacy women reporting higher self-esteem $(M=0.79, S D=1.35)$ than low efficacy women $(M=-0.36, S D=1.11)$. There was a significant interaction between leadership efficacy and stereotype activation $(F(1,67)=5.10, p<.03$, $\eta^{2}=.07$; see Figure 4) such that high efficacy women primed with the stereotype reported higher levels of self-esteem $(M=1.30, S E=0.28)$ than those primed with the neutral material $(M=0.25, S E=0.29$; simple $F(1,67)=6.85, p<.02$, $\left.\eta^{2}=.09\right)$. Low efficacy leaders primed with the
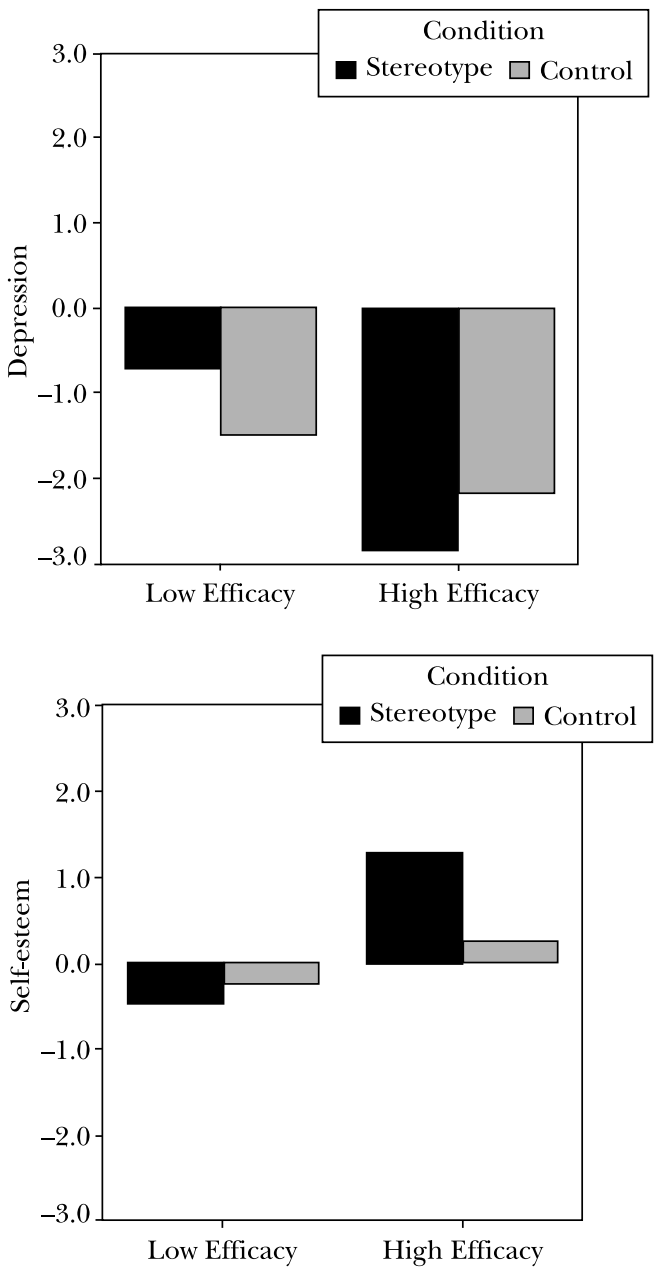

Figure 4. The impact of leadership efficacy and stereotype activation on self-esteem and depressed affect (Study 2).

stereotype did not report significantly different levels of self-esteem $(M=-0.47, S E=0.28)$ compared to those in the control condition $(M=-0.25$, $S E=0.28)$, simple $F(1,67)=.32, \mathrm{~ns})$.

Depressed affect The main effect for stereotype activation on depressed affect was not significant $(p>.80)$. There was a significant main effect for efficacy $\left(F(1,66)=17.04, p<.001, \eta^{2}=.21\right)$, such that high efficacy women reported less depressed affect $(M=-2.52, S D=1.17)$ than low efficacy women $(M=-1.11, S D=1.69)$. As predicted, 
there was a significant interaction between leadership efficacy and stereotype activation on the leaders' self-reported depressed affect $\left(F(1,66)=4.48, p<.04, \eta^{2}=.06\right)$ (see Figure 4) Testing the simple effects of stereotype activation revealed no significant effect of stereotype activation on self-reported depressed affect for either high efficacy ( simple $F(1,66)=1.80$, $p>.15$ ) or low efficacy ( simple $F(1,66)=2.74$, $p>.10)$ women. However, testing the simple effects of leadership efficacy indicated that although in the control condition high and low efficacy women report similar levels of depressed affect $(\operatorname{simple} F(1,66)=2.02, p>.15)$, when primed with the stereotype high efficacy women reported significantly lower levels of depressed affect $(M=-2.85, S D=.35)$ than low efficacy leaders $(M=-0.71, S D=0.34)$ (simple $\left.F(1,66)=19.49, p<.001, \eta^{2}=.23\right)$.

\section{Mediation hypotheses}

Domain identification Data from both studies were used in this analysis. Regression techniques were used to test whether the hypothesized significant interaction between stereotype activation and leadership efficacy on domain identification was mediated by perceived performance (Baron \& Kenny, 1986). To test this mediated moderation, the interaction term was computed and domain identification was regressed on the main effects and the interaction of stereotype activation and leadership efficacy to determine the total percentage of variance explained by the interaction. As expected from the analysis of variance results above, the interaction coefficient was significant $(\beta=.15$, $p<.05)$. To meet the second criterion for mediation, the mediator must be significantly predicted by the interaction between leadership efficacy and stereotype activation. Stereotype activation and leadership efficacy had significant interactive effects on perceived performance $(\beta=.23, p<.01)$.

To test the remaining criteria for mediation, a hierarchical regression analysis was performed. Predicting domain identification, the main effects for leadership efficacy and stereotype activation were entered on Step 1, the mediator, perceived performance, was entered on Step 2, and finally, the interaction term was entered in the third step. The next criterion was to show that the mediator variable was significantly related to the dependent variable. Consistent with this criterion, in Step 2 perceived performance significantly predicted domain identification $(\beta=.32, p<.001)$. The final criterion for mediation is that the original interaction term should be substantially reduced or eliminated when the mediator is entered into the analysis. Indeed, in Step 3 the interaction term was no longer significant $(\beta=.08, p>.15)$ and perceived performance significantly predicted domain identification $(\beta=.30 p=.001$; refer to Table 1 and see Figure 3$).^{6}$

Additionally, using the raw regression coefficients and the standard errors from the analyses above, the Goodman (I) version of the Sobel test statistic was calculated to test whether the effect of the interaction between leadership efficacy and stereotype activation on domain identification via perceived performance is significantly different from zero (Baron \& Kenney, 1986; Sobel, 1982.) The Sobel test statistic was significant $(Z=2.37, p<.02)$, indicating that perceptions of performance seem to carry the interactive influence of leader efficacy and stereotype activation on domain identification.

Self-esteem Next, the hypothesis that the interaction between stereotype activation and leadership efficacy on self-esteem would be mediated by perceived performance was tested (refer to Table 1); self-esteem data were collected only in Study 2. As expected, the interaction coefficient significantly predicted self-esteem $(\beta=.24$, $p<.05)$ and perceived performance $(\beta=.21$, $p<.05)$. Using a similar hierarchical regression analysis as above, perceived performance significantly predicted self-esteem in Step 2 $(\beta=.57, p<.001)$. When the interaction term was entered into the equation with perceived performance it no longer significantly predicted self-esteem $(\beta=.12, p>.15)$, however, perceived performance still significantly predicted selfesteem $(\beta=.54, p<.001)$.

Finally, to test whether the effect was different from zero we calculated the Goodman (I) 
Table 1. Summary of hierarchical regression analyses testing perceived performance as a mediator of the interaction between leadership efficacy and stereotype activation on domain identification (studies 1 and 2 combined), self-esteem, and depressed affect (Study 2 only)

Mediator:

With no mediator Perceived performance

Domain identification

Step 1

Main effects ${ }^{\mathrm{a}}$

$R^{2}$

$\beta$

$\Delta R^{2}$

Step 3

Efficacy $\times$ Stereotype

Mediator

Self-esteem

Step 1

Main effects ${ }^{\mathrm{a}}$

Step 2

Mediator

Step 3

Efficacy $\times$ Stereotype

Mediator

Depressed affect

Step 1

Main effects ${ }^{\mathrm{a}}$

Step 2

Mediator

Step 3

Efficacy $\times$ Stereotype

Mediator

$\beta$

$\Delta R^{2}$

$\beta$

$R^{2}$

$\beta$

$\Delta R^{2}$

$\beta$
$\Delta R^{2}$
$\beta$

$R^{2}$

$\beta$
$\Delta R^{2}$
$47.8 \%$

$\begin{array}{lc}- & .32 * * * \\ - & 8.3 \%\end{array}$

$19.5 \%$

$-$

$-$

$.23 *$

$5.1 \%$
$19.5 \%$

$47.8 \%$

$8.3 \%$

.08

$0.6 \%$

$.30 * * *$

$20.5 \%$

$.57 * * *$

$24.6 \%$

.12

$1.4 \%$

$.54 * * *$

$-.54 * * *$

$22.1 \%$

.11

$1.2 \%$

$-.51 * * *$

${ }^{\mathrm{a}}$ Block includes leadership efficacy and stereotype activation.

$* p<.05 ; * * p<.01 ; * * * p<.001$.

version of the Sobel test statistic which revealed a marginal level of significance $(Z=1.89, p<.06)$. Taken together, these mediational analyses indicate that perceived performance mediates the interaction between stereotype activation and leadership efficacy on self-esteem (see Figure 5).

Depressed affect Finally, using data from Study 2, the hypothesis that the interaction between stereotype activation and leadership efficacy on depressed affect would be mediated by perceived performance was tested (see Table 1). First, as expected, the interaction coefficient between self-efficacy and stereotype activation significantly predicted depressed affect $(\beta=.23$, $p<.05)$. Using hierarchical regression, perceived performance significantly predicted depressed affect in Step 2, after the main effects were entered into the equation $(\beta=-.54, p<.001)$. When the interaction term was entered in Step 3 it no longer significantly predicted depressed affect $(\beta=.11, p>.20)$ and perceived performance still significantly predicted depressed affect 

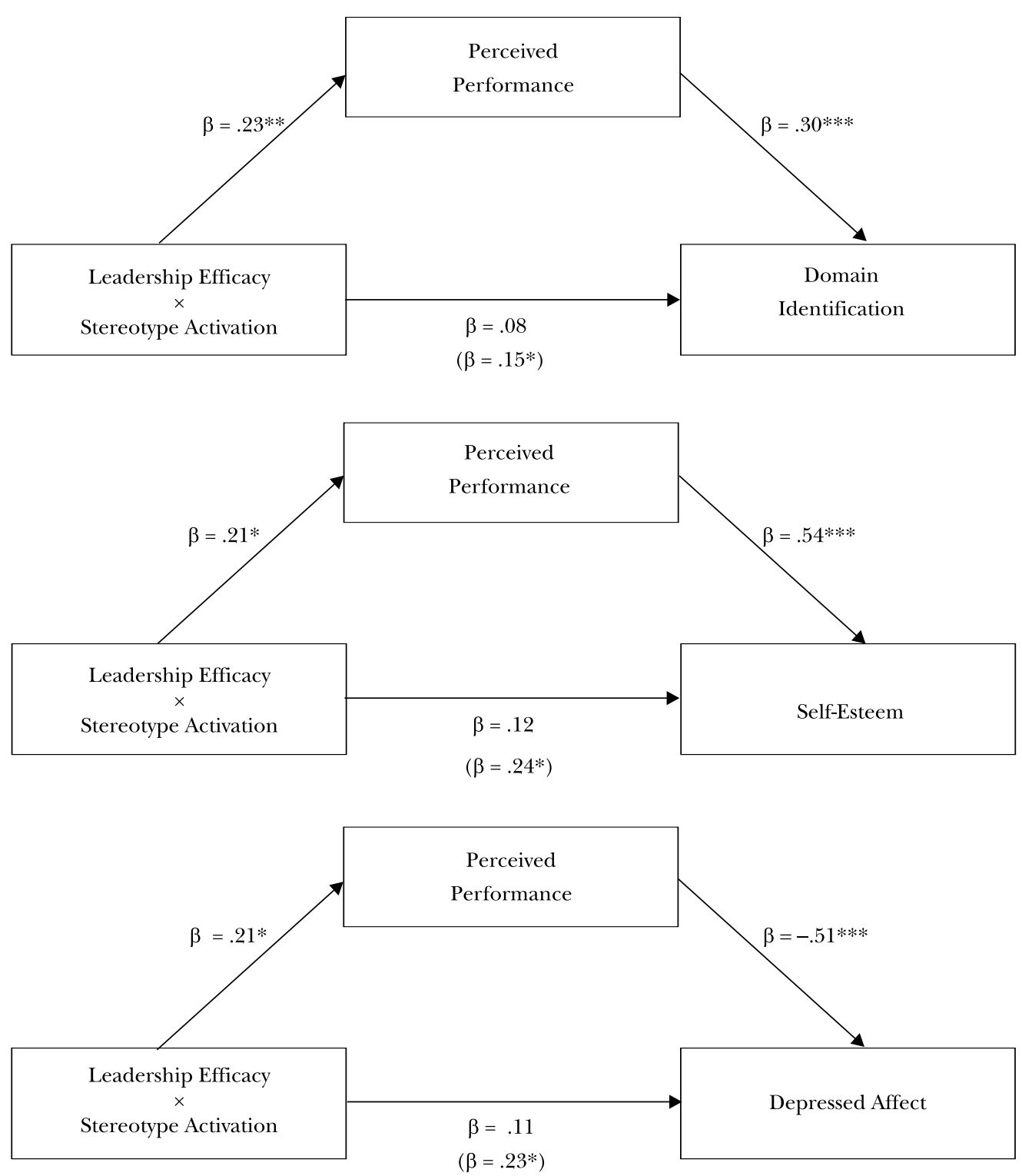

${ }^{*} p<.05 ; * * p<.01 ; * * * p<.001$.

Figure 5. Perceived performance as a mediator of the interactive effects of leadership efficacy and stereotype activation on domain identification, self-esteem (Study 2), and depressed affect (Study 2).

$(\beta=-.51, p<.001)$. Finally, the Goodman (I) Sobel test statistic was marginally significant $(Z=1.84, p<.07)$. Thus, perceived performance also appears to be a successful mediator of the interaction between leadership efficacy and stereotype activation on depressed affect (see Figure 5). 


\section{General discussion}

Substantial evidence highlights the incongruity between the female gender stereotype and the leadership role (Eagly \& Karau, 2002). This research examined how this incongruity affects female leaders. More specifically, this research tested the moderating role of leadership efficacy on women leaders' responses to the negative stereotype regarding female leaders. In this research, it was predicted that when blatantly presented with the gender leader stereotype high efficacy leaders would exhibit reactance to the stereotype; these hypotheses were strongly supported across the two studies.

Leadership tasks often lack clear, immediate markers of success. On such tasks, the leaders' immediate subjective sense of how well they performed becomes quite important. The hypothesis that stereotype activation would serve to increase high efficacy leaders' perceived performance was supported. In addition, high efficacy leaders were rated as performing better in the stereotype activation condition compared to the control condition. Domain identification was another outcome examined in these studies. The seminal work on stereotype threat proposed that one approach individuals may take to cope with the threat is to protectively disidentify with the domain (Steele \& Aronson, 1995). Our reactance prediction that high efficacy women would evince heightened identification with the domain was supported.

Finally, previous research highlights the deleterious effects that negative stereotypes can have on the psychological well-being of the targets of the stereotypes (Swim et al., 2001). The present research tested the hypothesis that high efficacy targets would show an increase in well-being in the face of stereotype activation. This hypothesis was tested and supported in Study 2 and both self-esteem and depressed affect were taken as indices of psychological wellbeing. It appears that stereotype activation has a positive effect on the self-esteem and depressed affect of high efficacy leaders.

A second objective of this research was to explore one possible mechanism accounting for changes in domain identification and psychological well-being resulting from stereotype activation: self-perception. That is, the present studies tested the hypotheses that the interaction between leadership efficacy and stereotype activation on leadership domain identification and psychological well-being would be mediated by the leader's perception of her performance on the leadership task. As hypothesized, regression analyses indicated that the effect of stereotype activation on high and low efficacy leaders' domain identification was mediated by the leaders' perceived performance. Moreover, perceived performance also appears to be a mechanism through which the leaders' self-reported well-being is influenced. These hypotheses were tested on both measures of well-being in Study 2 and were supported.

It is important to note that reverse causal effects for the mediation results cannot completely be ruled out in the present research. That is, it may be the case that domain identification and wellbeing 'cause' perceived performance. However, this alternative interpretation is less plausible when considering the theoretical work on selfperception theory, which describes the importance of self-perception on inferences regarding one's traits and attitudes (Bem, 1967), and the work on the sources of self-esteem which demonstrates the important impact of perceived personal competence and living up to one's personal standards of merit on self-esteem (Bandura, 1997). Our causal interpretation is also consistent with the theoretical and empirical work showing that attributing successful performance outcomes to internal causes, such as ability or effort, raises self-esteem (Hoyt, Aguilar, Kaiser, Blascovich, \& Lee, in press; Weiner, 1985). Additionally, empirical research testing alternative causal models between actual and perceived performance and selfesteem also supports our causal interpretation (Bohrnstedt \& Felson, 1983). In sum, perceived performance appears to play an important mediating role in the domain identification and well-being effects of stereotype activation on women leaders; however, due to the correlational nature of this research a better understanding 
of the causal relationships between perceived performance, domain identification, and wellbeing merits further investigation.

\section{Implications}

Theoretical This research expands our understanding of the effects of stereotypes beyond the academic domain to the domain of leadership. While investigations into the role stereotype activation plays within domains other than academia, such as decision task performance (Leyens, Désert, Croset, Darcis, 2000), has begun, understanding the effects of stereotype activation across domains is in its infancy. In addition, these experiments examined rated performance as well as self-concept outcomes deemed important in these situations: perceived performance, domain identification, and psychological well-being. Thus, the results from the present research highlight the important role that stereotype activation plays in influencing theoretically relevant self-concept variables.

Next, a comprehensive understanding of the nature of stereotype activation should include an insight into important moderator variables. Previous research has documented both situational and individual difference moderators of stereotype threat. For example, task difficulty and frustration, test diagnosticity, and stereotype relevance are situational factors that moderate reactions to stereotype threat, whereas domain identification, stigma consciousness, and identification with the group to which the negative stereotype applies are individual difference moderators (Aronson et al., 1999; Blascovich, Spencer, Quinn, \& Steele, 2001; Pinel, 1999; Schmader, 2002; Spencer, Iserman, Davies, \& Quinn, 2001; Steele \& Aronson, 1995). The current research demonstrates another important individual difference variable that moderates reactions to stereotype activation: self-efficacy.

While this work has provided a deeper understanding about domain generalizability, outcomes, and moderators of stereotype activation effects, an equally important theoretical advancement of this work includes understanding that, at times, stereotype activation can have a positive effect on performance. Until recently, research has primarily shown stereotype activation to either have no effect or to be damaging to the targets of that stereotype. The present research supports recent research by underscoring the counterintuitive notion that stereotype activation can actually elicit positive responses from targets of the stereotypes (Kray et al., 2004). Finally, this work highlights the role of perceived performance in influencing the leaders' identification with the leadership domain and their psychological well-being. Perceptions of one's performance seem to be an important source of immediate feedback that appears to play a role in domain identification and psychological well-being.

Applied value This line of research not only provides important contributions to social psychological theory, but it also contributes to a practical understanding of the unique challenges that women face in the realm of leadership. This research points to the resilience of women who are highly confident in their leadership abilities and are able to rise to the occasion in the face of negative stereotypes. When confronted with the stereotype these women perceive they perform better, are rated as performing better, become more identified with the domain of leadership, and have greater psychological well-being.

While we cannot ascertain causality with the approach taken in this research, these findings reveal that efficacy clearly moderates reactions to stereotype activation. Thus, in a more applied vein, knowing the important moderating role of efficacy helps to identify those who may be more or less adversely affected by stereotype activation. Consequently, interventions designed to foster more positive responses to stereotype activation can be focused on those most likely to benefit: those with low self-efficacy. Recent research has suggested that making group achievements salient (focusing on successful women mathematicians) helps alleviate women's mathematical stereotype threat (McIntyre, Paulson, \& Lord, 2003). Thus, presenting low efficacy women with examples of successful women leaders may be effective in encouraging more positive responses to stereotype activation in the leadership domain. 
Finally, this research examined leadership within an immersive virtual environment. Given the expansion of the virtual workplace, these findings are directly relevant to current organizational trends. Additionally, the success of this research paradigm lends credibility to the use of IVET in the study of leadership. Indeed, IVET is a promising tool for the study of leadership by researchers as well as organizations.

\section{Limitations and future directions}

It is important to point out that the current findings are somewhat inconsistent with findings from the stereotype threat literature. In most of the stereotype threat research, the participants selected for the studies are those highly identified with the academic domain under study. Indeed, studies designed to test the role of domain identification in the stereotype threat paradigm generally reveal that stereotype threat effects occur only for those who are highly identified with the domain (Aronson et al., 1999). The results of the present research indicate that stereotype activation had positive effects on those who have high efficacy in their leadership abilities. Because self-efficacy and domain identification are related constructs, the results from the present research and the stereotype threat literature are somewhat at odds.

There are a few factors that may help explain the contradictory findings; these factors should be further investigated. First and foremost, stereotypes were activated blatantly in this research. The relative explicit vs. implicit manner in which the stereotype is primed has been shown to play an important role in responses to these stereotypes (Kray et al., 2001). For example, recent research revealed that women primed with implicit gender stereotypes showed less of a preference for a leadership role compared to those not primed with the stereotype (Davies, Spencer, \& Quinn, 2002). Stoddard et al. (2003) also found that subtle stereotypes evoked assimilation patterns such that women were less likely to desire a leadership role; however, they also found that blatant stereotypes resulted in women demonstrating an increased desire to assume a leadership position. Thus, previous research indicates that subtle stereotype activation has a particularly pernicious effect on the targets of the stereotypes. The impact of more subtle stereotype activation on high and low efficacy leaders is an important empirical question that merits further investigation.

Other differences between this research and stereotype threat research involve the differing domains, tasks, and outcome measures. First, the stereotype relevant domain often examined in the stereotype threat literature is an academic domain. The academic and leadership domains differ on a number of factors including the extent to which there are objective measures of success. It may be that the effects of stereotype activation are different in the domain of leadership than the domain of academia, or on tasks that either lack or have objective performance markers. Indeed the leadership task may not have engendered the level of frustration often encountered in academic tasks, and task frustration has been implicated as a key component of the stereotype threat process (Steele \& Aronson, 1995). Additionally, the outcomes examined in this research differ from the classic stereotype threat outcomes. That is, the stereotype threat literature often examines objective performance on an academic exam whereas the outcomes examined here were subjective performance ratings and self-concept outcomes associated with task performance. Stereotypes may not affect these varying responses in the same manner. A full examination of the parameters of the effect will likely elucidate the apparent contradiction in findings.

Determining the causal role of efficacy Future research should attempt to determine the causal role of leadership efficacy in the observed effects. According to Bandura (1997), there are four sources of efficacy information: enactive mastery, vicarious experiences, verbal persuasion, and physiological and affective states. Future research should take a well-rounded approach to manipulating efficacy by focusing on these principal sources. Perhaps a promising approach to understanding the causal role of efficacy in the observed effects would be to develop a comprehensive efficacy-training program, including methods from each of the four sources of 
efficacy information. Examining and comparing responses to stereotype activation of low efficacy women who have and have not had the training may provide us with insight into the causal role of efficacy in reactions to stereotype activation. Additionally, the role of efficacy in reactions to stereotype activation in other domains should be evaluated.

\section{Conclusions}

The incongruity between the leadership role and the female gender role has important implications for women leaders. The current research highlights the role of leadership efficacy in responses to negative stereotypes in the domain of leadership. As demonstrated here, stereotype activation can actually be associated with beneficial responses-but only for women who have high self-efficacy for leadership. Currently, most research is focused on examining the debilitating effects that negative stereotypes have on the targets of these stereotypes. Hopefully this work will open up an avenue of investigation into the more beneficial responses to these stereotypes. A better understanding of high efficacy leaders' responses to stereotype activation may provide us with tools to counter the more detrimental responses of those lacking efficacy.

\section{Notes}

1. Researchers have adopted varying labels for the distinction between the descriptive and prescriptive aspects of gender stereotypes. Eagly and Karau (2002) use role terminology, referring to the descriptive and injunctive aspects of gender roles, whereas others use stereotype terminology, referring to descriptive stereotypes, or gender stereotypes, and prescriptive stereotypes (Burgess \& Borgida, 1999). This paper makes no distinction between the terms and uses them interchangeably.

2. In this manuscript, priming the stereotype refers to the general operationalization of stereotype activation.

3. Technology specifications: The head mounted display was a Virtual Research V8 HMD (a stereoscopic display with dual 680 horizontal by 480 vertical resolution LCD panels that refresh at $72 \mathrm{~Hz}$ ). The optics of this display presented a visual stimulus subtending approximately 50 degrees horizontally by 38 degrees vertically. Perspectively correct stereoscopic images were rendered by a 450 $\mathrm{MHz}$ Pentium III dual processor computer with an Evans \& Sutherland Tornado 3000 dual pipe graphics card, and these images were updated at an average frame rate of $36 \mathrm{~Hz}$. The simulated viewpoint was continually updated by the participants' head movements. The orientation of the participant's head was tracked by a three-axis orientation sensing system (Intersense IS300, update rate of $150 \mathrm{~Hz}$ ). The system latency, or the amount of delay between a participant's head motion and the resulting concomitant update in the HMD's visual display, was $65 \mathrm{~ms}$ maximum.

4. During debriefing only four participants indicated suspicion that there were no other participants. Across both studies, analyses with and without suspicious participants yield similar results.

5. These statistics were accurate at the time the experiment was conducted.

6. Importantly, reverse causal effects cannot completely be ruled out. That is, oftentimes in mediational analyses if the mediator and the outcome variable are interchanged, the outcome seems to 'cause' the mediator (Kenny, Kashy, \& Bolger, 1998). Accordingly, in the present research interchanging perceived performance with the outcome variables yielded significant mediational effects. However, the plausibility of reverse causation is weakened by the experimental design in which the mediator was measured temporally prior to the outcome variables. The analyses in this manuscript focus on the causal paths based on a priori theoretical predictions.

\section{Acknowledgements}

This work was supported in part by NSF ITR Award \#0205740 to the second author. We acknowledge and thank Lauren Aguilar, Donovan Bean, Missy Clayton, Michelle Dennis, Sarah Estrada, Lauren Gase, Sarah Haskell, Diana Hill, Annie Lamson, Kevin Lee, Elizabeth LeMoine, Cari Nicholson, and Peter Westphalen for their superb contributions to this research. 


\section{References}

Arkkelin, D., \& Simmons, R. (1985). The 'good manager': Sex-typed, androgynous, or likable? Sex Roles, 12, 1187-1198.

Aronson, J., Lustina, M. J., Good, C., Keough, K., Steele, C. M., \& Brown, J. (1999). When White men can't do math: Necessary and sufficient factors in stereotype threat. Journal of Experimental Social Psychology, 35, 29-46.

Aronson, J., Quinn, D. M., \& Spencer, S. J. (1998). Stereotype threat and the academic underperformance of minorities and women. In J. K. Swim \& C. Stangor (Eds.), Prejudice: The target's perspective (pp. 83-103). San Diego, CA: Academic Press, Inc.

Bandura, A. (1982). Self-efficacy mechanism in human agency. American Psychologist, 37, 122-147.

Bandura, A. (1986). Social foundations of thought and action. Englewood Cliffs, NJ: Prentice-Hall.

Bandura, A. (1997). Self-efficacy: The exercise of control. New York: W.H. Freeman.

Bandura, A., \& Cervone, D. (1983). Self-evaluative and self-efficacy mechanisms governing the motivational effects of goal systems. Journal of Personality and Social Psychology, 45, 1017-1028.

Bandura, A., \& Wood, R. (1989). Effect of perceived controllability and performance standards on self-regulation of complex decision-making. Journal of Personality and Social Psychology, 56, 805-814.

Barling, J., \& Beattie, R. (1983). Self-efficacy beliefs and sales performance. Journal of Organizational Behavior Management, 5, 41-51.

Baron, R. M., \& Kenny, D. A. (1986). The moderator-mediator variable distinction in social psychological research: Conceptual, strategic and statistical considerations. Journal of Personality and Social Psychology, 51, 1173-1182.

Bem, D. (1967). Self-perception: An alternative interpretation of cognitive dissonance phenomena. Psychological Review, 74, 183-200.

Bergeron, D.M., Block, C.J., \& Echtenkamp, B.A. (2006). Disabling the able: Stereotype threat and women's work performance. Human Performance, 19, 133-158.

Blascovich, J., Loomis, J., Beall, A., Swinth, K., Hoyt, C., \& Bailenson, J. (2002). Immersive virtual environment technology as a methodological tool for social psychology. Psychological Inquiry, 13, 103-125

Blascovich, J., Spencer, S. J., Quinn, D., \& Steele, C. (2001). African Americans and high blood pressure: The role of stereotype threat. Psychological Science, 12, 225-229.
Bohrnstedt, G. W., \& Felson, R. (1983).

Explaining the relations among children's actual and perceived performances and selfesteem: A comparison of several causal models. Journal of Personality and Social Psychology, 45, 43-56.

Boldry, J., Wood, W., \& Kashy, D. A. (2001). Gender stereotypes and the evaluation of men and women in military training. Journal of Social Issues, 57, 689-705.

Brehm, J. W. (1966). A theory of psychological reactance. New York: Academic Press.

Broverman, I.K., Vogel, S.R., Broverman, D.M., Clarkson, F.E., \& Rosenkrantz, P.S. (1972). Sex-role stereotypes: A current reappraisal. Journal of Social Issues, 28, 59-78.

Bureau of Labor Statistics (2006). Women in the labor force: A databook. Retrieved 2 December 2006 from: http://www.bls.gov/cps/wlf-databook2006.pdf

Burgess, D., \& Borgida, E. (1999). Who women are, who women should be: Descriptive and prescriptive gender stereotyping in sex discrimination. Psychology, Public Policy, E Law, 5, 665-692.

Campbell, N.K., \& Hackett, G. (1986). The effects of mathematics task performance on math selfefficacy and task interest. Journal of Vocational Behavior, 28, 149-162.

Carli, L. L. (2001). Gender and social influence. Journal of Social Issues, 57, 725-741.

Carli, L.L., \& Eagly, A. H. (2001). Gender, hierarchy, and leadership: An introduction. Journal of Social Issues, 57, 629-636.

Catalyst (2002). Catalyst census of women corporate officers and top earners. New York: Catalyst.

Chemers, M. M., Watson, C. B., \& May, S. (2000). Dispositional affect and leadership effectiveness: A comparison of self-esteem, optimism and efficacy. Personality and Social Psychology Bulletin, 26, 267-277.

Davies, P.G., Spencer, S. J., \& Quinn, D. M. (2002). Consuming images: How television commercials that elicit stereotype threat can restrain women academically and professionally. Personality and Social Psychology Bulletin, 28, 1615-1628.

Davies, P. G., Spencer, S. J., \& Steele, C. M. (2005). Clearing the air: Identity safety moderates the effects of stereotype threat on women's leadership aspirations. Journal of Personality and Social Psychology, 88, 276-287.

Deaux, K., \& Lewis, L. L. (1983). Components of gender stereotypes. Psychological Documents, 13(2), MS. 258325. 
Deaux, K., \& Lewis, L. L. (1984). Structure of gender stereotypes: Inter-relationships among components and gender label. Journal of Personality and Social Psychology, 46, 991-1004.

Dodge, K.A., Gilroy, F. D., \& Fenzel, L. M. (1995). Requisite management characteristics revisited: Two decades later. Journal of Social Behavior E Personality, 10, 253-264.

Eagly, A. H. (1987). Sex differences in social behavior: A social-role interpretation. Hillsdale, NJ: Erlbaum.

Eagly, A. H., \& Karau, S. (2002). Role congruity theory of prejudice toward female leaders. Psychological Review, 109, 573-598.

Eagly, A. H., Makhijani, M. G., \& Klonsky, B. G. (1992). Gender and the evaluation of leaders: A meta-analysis. Psychological Bulletin, 111, 3-22.

Eagly, A. H., Wood, W., \& Diekman, A. B. (2000). Social role theory of sex differences and similarities: A current appraisal. In T. Eckes \& H. M. Trautner (Eds.), The developmental social psychology of gender (pp. 123-174). Mahwah, NJ: Erlbaum.

Eckes, T. (1994). Explorations in gender cognition: Content and structure of female and male subtypes. Social Cognition, 12, 37-60.

Glick, P., \& Fiske, S. T. (1996). The Ambivalent Sexism Inventory: Differentiating hostile and benevolent sexism. Journal of Personality and Social Psychology, 70, 491-512.

Glick, P., \& Fiske, S. T. (1999). Sexism and other 'isms': Independence, status, and the ambivalent content of stereotypes. In W. B. Swann, Jr. \& J. H. Langlois (Eds.), Sexism and stereotypes in modern society: The gender science of Janet Taylor Spence (pp. 193-221).Washington, D.C.: American Psychological Association.

Heatherton, T.F., \& Polivy, J. (1991). Development and validation of a scale for measuring state selfesteem. Journal of Personality and Social Psychology, 60, 895-910.

Heilman, M. E. (2001). Description and prescription: How gender stereotypes prevent women's ascent up the organizational ladder. Journal of Social Issues, 57, 657-674.

Heilman, M. E., Block, C. J., \& Martell, R. F.(1995). Sex stereotypes: Do they influence perceptions of managers? Journal of Social Behavior and Personality, 10, 237-252.

Heilman, M. E., Block, C. J., Martell, R. F., \& Simon, M. C. (1989). Has anything changed? Current characterizations of men, women and managers. Journal of Applied Psychology, 74, 935-942.
Hill, T., Smith, N.D., \& Mann, M.F. (1987). Role of efficacy expectations in predicting the decision to use advanced technologies. Journal of Applied Psychology, 72, 307-314.

Hoyt, C., Aguilar, L., Kaiser, C., Blascovich, J., \& Lee, K. (in press). The self-protective and undermining effects of attributional ambiguity. Journal of Experimental Social Psychology.

Inzlicht, M., \& Ben-Zeev, T. (2000). A threatening intellectual environment: Why females are susceptible to experiencing problem-solving deficits in the presence of males. Psychological Science, 11, 365-371.

Jex, S. M., \& Bliese, P. D. (1999). Efficacy beliefs as a moderator of the impact of work-related stressors: A multilevel study. Journal of Applied Psychology, 84, 349-361.

Joyce, A. (2006, 15 August). Fortune 500 gains female CEO in new PepsiCo chief. The Washington Post, pp. D01.

Kenny, D. A., Kashy, D. A., \& Bolger, N. (1998). Data analysis in social psychology. In D. Gilbert, S. Fiske, \& G. Lindzey (Eds.), The handbook of social psychology (Vol. 1, 4th ed., pp. 233-265). Boston, MA: McGraw-Hill.

Kray, L., Reb, J., Galinsky, A. \& Thompson, L. (2004). Stereotype reactance at the bargaining table: The effect of stereotype activation and power on claiming and creating value. Personality and Social Psychology Bulletin, 30, 399-411.

Kray, L. J., Thompson, L., \& Galinsky, A. (2001). Battle of the sexes: Gender stereotype confirmation and reactance in negotiations. Journal of Personality and Social Psychology, 80, 942-958.

Lazarus, R. S., \& Folkman, S. (1984). Stress, coping, and adaptation. New York: Springer.

Lent, R.W., Brown, S.D., \& Larkin, K.C. (1987). Comparison of three theoretically derived variables in predicting career and academic behavior: Self-efficacy, interest congruence, and consequence thinking. Journal of Counseling Psychology, 34, 293-298.

Leyens, J., Désert, M., Croizet, J., \& Darcis, C. (2000). Stereotype threat: Are lower status and history of stigmatization preconditions of stereotype threat? Personality $\mathcal{E}$ Social Psychology Bulletin, 26, 1189-1199.

Lubin, B., Zuckerman, M., \& Woodward, L. (1985). Bibilography for the Multiple Affect Adjective Check List. San Diego, CA: Educational and Industrial Testing Service. 
Major, B., Spencer, S., Schmader, T., Wolfe, C., \& Crocker, J. (1998). Coping with negative stereotypes about intellectual performance: The role of psychological disengagement. Personality E Social Psychology Bulletin, 24, 34-50.

Martell, R. F., Parker, C., Emrich, C. G., \& Crawford, M. S. (1998). Sex stereotyping in the executive suite: 'Much ado about something'. Journal of Social Behavior and Personality, 13, 127-138.

McIntyre, R. B., Paulson, R. M., \& Lord, C. G. (2003). Alleviating women's mathematics stereotype threat through salience of group achievements. Journal of Experimental Social Psychology, 39, 83-90.

Murphy, S. E. (1992). The contribution of leadership experience and self-efficacy to group performance under evaluation apprehension. Unpublished doctoral dissertation, University of Washington, Seattle.

Murphy, S. E., Chemers, M. M., Kohles, J., \& Macaulay, J. L. (2004). The contribution of leadership self-efficacy to performance under stress: An extension of cognitive resources theory. Unpublished manuscript.

Murphy, S. E. (2002). Leader self-regulation: The role of self-efficacy and multiple intelligences. In R.E. Riggio \& S. E. Murphy (Eds.), Multiple intelligences and leadership (pp. 163-186). Mahwah, NJ: Lawrence Erlbaum and Associates.

Pinel, E. C. (1999). Stigma consciousness: The psychological legacy of social stereotypes. Journal of Personality and Social Psychology, 76, 114-128.

Powell, G. N., \& Butterfield, D. A. (1979). The 'good manager': Masculine or androgynous? Academy of Management Journal, 22, 395-403.

Powell, G. N., \& Butterfield, D. A. (1984). If 'good managers' are masculine, what are 'bad managers'? Sex Roles, 10, 477-484.

Powell, G. N., \& Butterfield, D. A. (1989). The 'good manager': Did androgyny fare better in the 1980s? Group and Organization Studies, 14, 216-233.

Ridgeway, C. L. (2001). Gender, status, and leadership. Journal of Social Issues, 57, 637-655.

Rosenwasser, S. M., \& Dean, N. G. (1989). Gender role and political office: Effects of perceived masculinity/femininity of candidate and political office. Psychology of Women Quarterly, 13, 77-85.

Rudman, L. A., \& Glick, P. (2001). Prescriptive gender stereotypes and backlash toward agentic women. Journal of Social Issues, 57, 743-762.
Schein, V. E. (1973). The relationship between sex role stereotypes and requisite management characteristics. Journal of Applied Psychology, 57, 95-100.

Schein, V. E. (2001). A global look at psychological barriers to women's progress in management. Journal of Social Issues, 57, 675-688.

Schmader, T. (2002). Gender identification moderates stereotype threat effects on women's math performance. Journal of Experimental Social Psychology, 38, 194-201.

Sczesny, S. (2003). A closer look beneath the surface: Various facets of the think-managerthink-male stereotype. Sex Roles, 49, 353-363.

Sekaquaptewa, D., \& Thompson, M. (2003). Solo status, stereotype threat, and performance expectancies: Their effects on women's performance. Journal of Experimental Social Psychology, 39, 68-74.

Sobel, M. E. (1982). Asymptotic intervals for indirect effects in structural equations models. In S. Leinhart (Ed.), Sociological methodology 1982 (pp. 290-312). San Francisco: Jossey-Bass.

Spencer, S. J., Iserman, E., Davies, P. G., \& Quinn, D. M. (2001). Suppression of doubts, anxiety, and stereotypes as a mediator of the effect of stereotype threat on women's math performance. Unpublished manuscript, University of Waterloo, Canada.

Steele, C. M., \& Aronson, J. (1995). Stereotype threat and the intellectual test performance of African Americans. Journal of Personality and Social Psychology, 69, 797-811.

Stoddard, T., Kliengklom, T., \& Ben-Zeev, T. (2003, February). Stereotype threat, assimilation, and contrast effects, and subtlety of priming, or: 'You say "Bitch" like it's a bad thing'. Paper presented at the annual Society for Personality and Social Psychology conference, Los Angeles, CA.

Stumpf, S. A., Brief, A. P., \& Hartman, K. (1987). Self-efficacy expectations and coping with career-related events. Journal of Vocational Behavior, 31, 91-108.

Swim, J. K., Hyers, L. L., Cohen, L. L., \& Ferguson, M. J. (2001). Everyday sexism: Evidence for its incidence, nature, and psychological impact from three daily diary studies. Special Issue: Stigma: An insider's perspective. Journal of Social Issues, 57, 31-53.

Taylor, M.S., Locke, E.A., Lee, C., \& Gist, M.E. (1984). Type A behavior and faculty research productivity: What are the mechanisms? Organizational Behavior and Human Decision Processes, 34, 402-418. 
Watson, C. B., Chemers, M. M., \& Preiser, N. (1996, June). Collective efficacy: A multi-level analysis. Presented at the annual meeting of the American Psychological Society, San Francisco, CA.

Weiner, B. (1985). An attributional theory of achievement motivation and emotion. Psychological Review, 92, 548-573.

White, J., \& Gardner, W. (2003, February). Confidence as a moderator of the effect of solo status on performance in a workgroup. Paper presented at the annual Society for Personality and Social Psychology conference, Los Angeles, CA.

Williams, J. E, \& Best, D. L. (1990). Sex and psyche: Gender and self viewed cross-culturally. Thousand Oaks, CA: Sage Publications, Inc.

Wood, W., Christensen, P. N., Hebl, M. R., \& Rothgerber, H. (1997). Conformity to sex-typed norms, affects, and the self-concept. Journal of Personality and Social Psychology, 73, 523-535.

Paper received 26 November 2005; revised version accepted 4 January 2007.

\section{Biographical Notes}

CRYSTAL HOYT completed her doctorate in social psychology at the University of California, Santa Barbara. She is currently an assistant professor at the Jepson School of Leadership Studies at the University of Richmond. Her curricular and research interests include social behavior, leadership and group dynamics, the effects of stereotypes and discrimination on women and minority leaders, the role of confidence in shaping group leadership, leader perception, and new methodological tools for social scientists.

JIM BLASCOVICH earned his PhD in social psychology at the University of Nevada, Reno. He is currently professor of psychology at the University of California, Santa Barbara. He co-directs the Research Center for Virtual Environments and Behavior. His main research interests include challenge and threat motivation, and the use of immersive virtual envirnment technology (IVET) as a methodological tool in social psychology. 